\title{
Investigation on neurotoxicity of occupational exposure to cyclohexane: a neurophysiological study
}

Junko Yuasa, Reiko Kishi, Teruko Eguchi, Izumi Harabuchi, Toshio Kawai, Masayuki Ikeda, Ryouichi Sugimoto, Hiroyuki Matsumoto, Hirotsugu Miyake

Objectives-To examine the effect of occupational exposure to cyclohexane on the peripheral nervous system.

Methods-A nerve conduction study was performed on 18 workers exposed to cyclohexane in a luggage factory and on age and sex matched occupationally unexposed controls. 12 workers had been exposed to $n$-hexane (median $2 \cdot 8$ years) before the start of exposure to cyclohexane. To confirm the effect of exposure, a follow up study was performed on nine workers one year after the first study. The mean exposure to cyclohexane was $1 \cdot 2$ years in the first study. A symptom survey was performed. The exposure was measured by air sampling of the breathing zone of each worker. The urinary metabolite cyclohexanol was also monitored.

Results-The concentration of airborne cyclohexane ranged from 5 to $211 \mathrm{ppm}$. The urinary concentration of cyclohexanol ranged from 0.12 to $1.51 \mathrm{mg} / 1$. There was a strong correlation between the cyclohexane exposure in personal air and urinary cyclohexanol. No differences were found in nerve conduction velocities (NCV) between workers exposed to cylohexane and age and sex matched controls. The results of the follow up study showed significant improvements in peroneal motor NCV $(P<0.01)$ and sural sensory NCV $(P<0.05)$ and in ulnar motor distal latency (MDL, $P<0.05$ ) and peroneal MDL $(P<0.05)$ compared with the first study. Although the past $\boldsymbol{n}$-hexane exposure affected the first neurophysiological study, the effect had disappeared in the second study, one year later.

Conclusion-Occupational exposure to the concentrations of cyclohexane experianced in this study had no adverse effects on the peripheral nervous system.

(Occup Environ Med 1996;53:174-179)

Keywords: cyclohexane; neurophysiological study; occupational exposure

Cyclohexane has been considered to be a solvent of low toxicity and is recommended as a substitute for other more toxic solvents such as $n$-hexane and benzene. ${ }^{1}$ However, studies on health effects of cyclohexane and its metabolite, cyclohexanone, are scarce. ${ }^{2-4}$ Although it is reported that for cyclohexane the margin between narcosis and death is very narrow and symptomatically barely recognisable, ${ }^{1}$ we considered that a neurophysiological study might detect the neurotoxicity of cyclohexane at a level of exposure too low to cause narcosis or death. Adverse effects on the peripheral nervous system in humans were reported, but this was not the case in rats. ${ }^{3-6}$ However, the exposure was not exclusive in the human studies; therefore, the adverse effect could not necessarily be attributed to cyclohexane.

The primary aim of this study was to examine the neurophysiological effects of occupational exposure to cyclohexane. This is the first study performed in a factory in which workers were exposed almost exclusively to this solvent. To more accurately determine the relation between cyclohexane and neurophysiological effects, a follow up study was performed in some workers.

The factory had used $n$-hexane in the past and shifted to cyclohexane gradually. Thus, we studied the neurotoxicity of cyclohexane considering the effects of past $n$-hexane exposure.

\section{Materials and methods}

The survey was conducted in a luggage factory. A glue containing $75.6 \%$ cyclohexane, $12.0 \%$ toluene, and $0.9 \% n$-hexane was used in the factory. ${ }^{7}$ The workers were selected as follows: (a) cyclohexane was found to be the main solvent to which the workers were exposed, according to the individual exposure data, ${ }^{7}(b)$ they had been engaged in the current job for more than half a year, and $(c)$ information was available on working conditions, alcohol, tobacco use, and subjective symptoms. Overall, 18 women met the requirements. Their ages ranged from 19 to 56 , with a mean (SD) of $24 \cdot 1(8 \cdot 5)$. They had been engaged in the current job for $0.4-2.6$ years $(1.2(0.6)$ years) at the time of our first study. On average, they were exposed to cyclohexane vapour for eight hours daily.

Twelve of the exposed workers had been engaged in work with $n$-hexane for $0 \cdot 3-20$ years (median 2.8 years), and stopped the work $0.7-2.6$ years (median 1.3 years) before the first investigation (fig).

Because of the small sample size of this study, the short duration of exposure to cyclohexane and short duration without exposure to $n$-hexane, we performed the follow up study one year after the first study to confirm the findings in the first study (fig). However, nine workers had moved to another department of the same factory or had left the job between 
Table 1 Characteristics of solvent workers and controls

\begin{tabular}{|c|c|c|c|}
\hline & $\begin{array}{l}\text { Solvent workers } \\
(n=18) \\
\text { Mean }(S D)\end{array}$ & $\begin{array}{l}\text { Controls } \\
(n=18) \\
\text { Mean }(S D)\end{array}$ & $P$ value \\
\hline $\begin{array}{l}\text { Age (y) } \\
\text { Education (y) } \\
\text { Height (cm) } \\
\text { Weight (kg) } \\
\text { Body mass index }\left(\mathrm{kg} / \mathrm{m}^{2}\right) \\
\text { Alcohol (ml ethanol } / \text { week) } \\
\text { Cigarettes (/day) }\end{array}$ & $\begin{array}{c}24 \cdot 1(8.5) \\
11 \cdot 6(1 \cdot 0) \\
154 \cdot 6(6 \cdot 1) \\
47 \cdot 2(4.5) \\
19 \cdot 7(1 \cdot 7) \\
40 \cdot 1(69 \cdot 9) \\
4.7(6.7)\end{array}$ & $\begin{array}{c}24 \cdot 7(8 \cdot 2) \\
15 \cdot 7(2 \cdot 2) \\
158 \cdot 7(4 \cdot 9) \\
51 \cdot 2(3.9) \\
20.3(1 \cdot 6) \\
30.2(46 \cdot 7) \\
0.1(0.5)\end{array}$ & $\begin{array}{l}\text { NS } \\
<0.01 \\
<0.01 \\
<0.01 \\
\text { NS } \\
\text { NS } \\
<0.01\end{array}$ \\
\hline $\begin{array}{l}\text { Skin temperature }\left({ }^{\circ} \mathrm{C}\right): \\
\text { Arm } \\
\text { Leg }\end{array}$ & $\begin{array}{l}33.6(1.2) \\
33.5(1.3)\end{array}$ & $\begin{array}{l}33.7(1.4) \\
33.1(1.4)\end{array}$ & $\begin{array}{l}\text { NS } \\
\text { NS }\end{array}$ \\
\hline
\end{tabular}

Number of subjects, the dates of examinations, and the history of use of solvents in the factory. the first and second studies. For this reason the follow up environmental and neurophysiological study was performed in only nine workers.

The control subjects (18 women) were recruited from among medical students and clerical workers. They were matched to the workers exposed to solvent by sex and age. Their mean (SD) age was $24 \cdot 7(8 \cdot 2)$.

Table 1 shows the characteristics of subjects. Workers exposed to solvent were significantly shorter and lighter than matched controls. The cigarette consumption of workers was higher than that of controls. All of the subjects had no known neurotoxic risks such as diabetes mellitus, alcohol or drug abuse, or neuropathy (including disk herniation).
SYMPTOM SURVEY

The questionnaire used in the symptom survey included questions about subjective symptoms both during work and when not at work in the past six months. In the symptom survey, background variables which could have influenced symptoms and neurophysiological measures, as potential confounders, were investigated (drinking habits, smoking habits, height, weight, years of education, and age). Occupational history was also studied in the survey. Three of 18 controls did not participate in the symptom survey. Among 61 symptoms, 20 general (weight loss, general fatigue, etc) and neurological symptoms were compared. Details of this survey were described previously. $^{8}$

\section{EVALUATION OF EXPOSURE}

The airborne cyclohexane of the breathing zone was collected for all workers with a diffusive sampler with activated carbon cloth (KF1500, Tokyo Company, Osaka, Japan) from the start of the working day to its end, ${ }^{9}$ over the whole eight hour shift. The urine at the end of the shift was collected and the concentration of urinary cyclohexanol was measured by the enzymatic hydrolysis method. These biological monitorings were performed in both the first and follow up studies. A detailed description of the procedure can be found in Yasugi et al. ${ }^{7}$ The past data on personal cyclo-

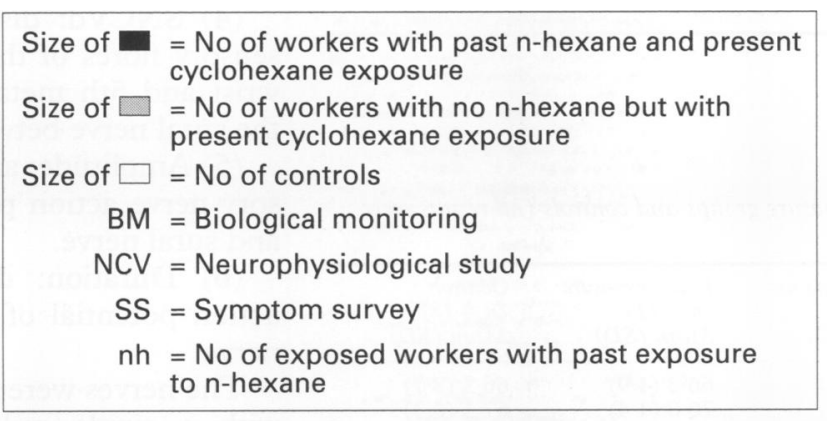

\section{A Subjects and dates of examinations}

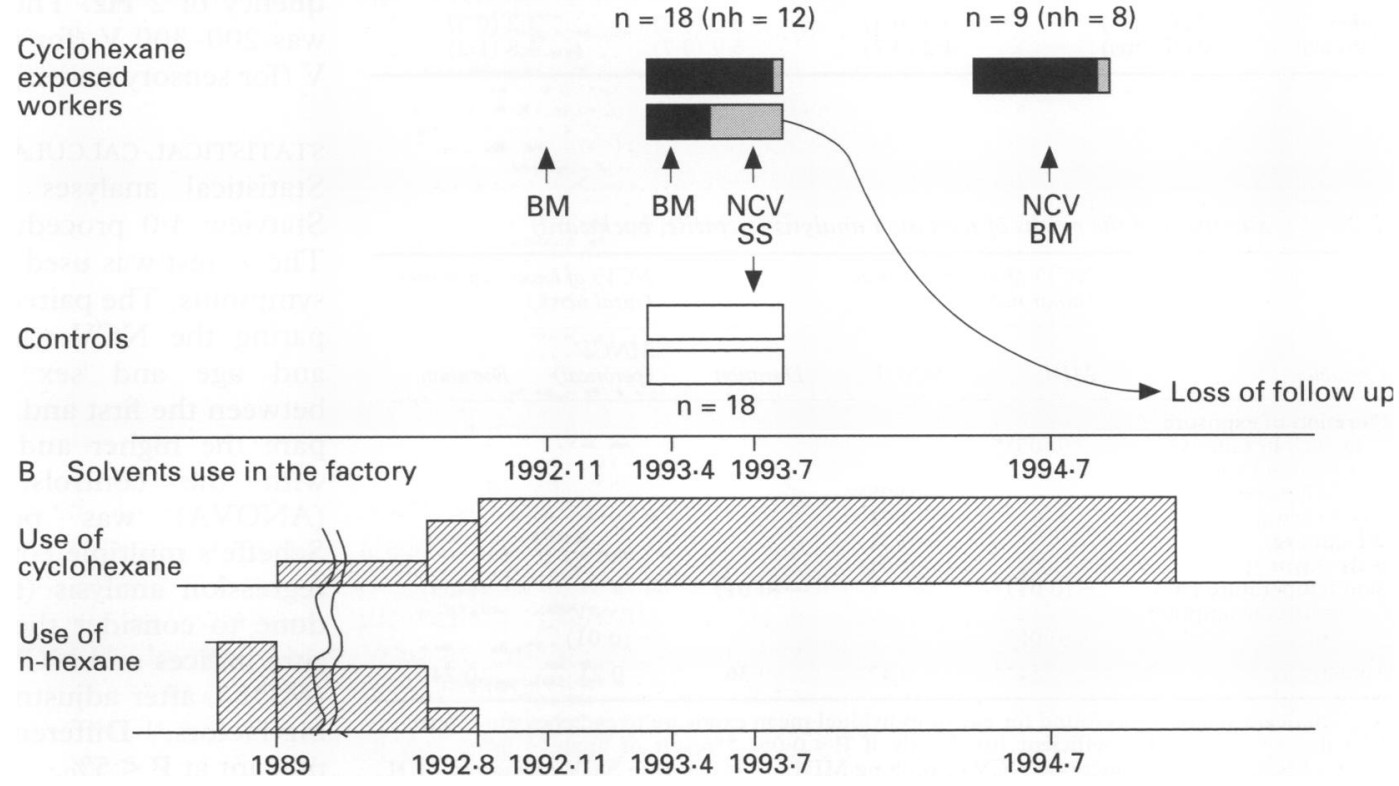


hexane exposure and urinary cyclohexanol measured by the same method used in the present study were available for some workers. To consider the relation between airborne cyclohexane and urinary metabolites, these data were used for analysis. According to the past and present exposure data, the workers were divided into higher $(n=7)$ and lower $(n=$ 11) exposure groups and nerve conduction velocities (NCVs) of each group were compared. The higher exposure group was the group whose mean cyclohexane exposure exceeded $100 \mathrm{ppm}$.

The previous exposure data showed that cyclohexane vapour is almost exclusively an air contaminant and the exposures to other solvents-for example, toluene, and $n$-hexanewere much lower. The cyclohexane concentration in air ranged from $13-720 \mathrm{ppm}$ (median

Table 2 Comparison of neurophysiological measurements between cydlohexane warker and matched controls (all results NS)

\begin{tabular}{|c|c|c|c|}
\hline & & $\begin{array}{l}\text { Solvent workers } \\
(n=18) \\
\text { Mean (SD) }\end{array}$ & $\begin{array}{l}\text { Comprols } \\
(n=18) \\
\text { Mean (SD) }\end{array}$ \\
\hline Ulnar & $\begin{array}{l}\text { MNCV } \\
\text { SNCVp } \\
\text { SNCVd }\end{array}$ & $\begin{array}{l}65 \cdot 6(4 \cdot 5) \\
70 \cdot 3(4 \cdot 7) \\
53 \cdot 2(4 \cdot 5)\end{array}$ & $\begin{array}{l}66 \cdot 3(3 \cdot 7) \\
67 \cdot 1(4 \cdot 3) \\
51 \cdot 7(4 \cdot 9)\end{array}$ \\
\hline Peroneal & MNCV & $51.6(3.3)$ & $53 \cdot 8 \cdot(5 \cdot 0)$ \\
\hline Sural & SNCV & $49 \cdot 5(8.4)$ & $51.8(6.7)$ \\
\hline Ulnar & MDL (ms) & $3 \cdot 2(0 \cdot 3)$ & $3 \cdot 2 \cdot(0 \cdot 3)$ \\
\hline Peroneal & MDL (ms) & $4.1(0.7)$ & $4.8(1: 2)$ \\
\hline \multirow[t]{2}{*}{ Ulnar } & Amplitude $(\mu \mathrm{V})$ & $20 \cdot 5(10: 3)$ & $25 \cdot 0(11.4)$ \\
\hline & Duration (ms) & $1.5(0.3)$ & $1.5(0.3)$ \\
\hline \multirow[t]{2}{*}{ Sural } & Amplitude $(\mu \mathrm{V})$ & $25 \cdot 7(12 \cdot 8)$ & $28 \cdot 8(14 \cdot 1)$ \\
\hline & Duration (ms) & $1.8(0.4)$ & $1.8(0.3)$ \\
\hline
\end{tabular}

Pairs were matched at the time of the first study.

Table 3 Comparison of higher and lower exposure groups and controls (all results were NS)

\begin{tabular}{lllll}
\hline & & $\begin{array}{l}\text { Higher exposure } \\
(n=7) \\
\text { Mean }(S D)\end{array}$ & $\begin{array}{l}\text { Lower exposutre } \\
(n=11) \\
\text { Mean }(S D)\end{array}$ & $\begin{array}{l}\text { Gortrols } \\
(n=18) \\
\text { Mean (SD) }\end{array}$ \\
\hline Ulnar & MNCV & $64 \cdot 5(3 \cdot 7)$ & $66 \cdot 3(4 \cdot 9)$ & $66 \cdot 3(3 \cdot 7)$ \\
& SNCVp & $70 \cdot 8(5 \cdot 4)$ & $70 \cdot 0(4 \cdot 4)$ & $67 \cdot 1(4 \cdot 3)$ \\
Peroneal & SNCVd & $53 \cdot 1(5 \cdot 9)$ & $53 \cdot 3(3 \cdot 6)$ & $51 \cdot 7 \cdot(4 \cdot 9)$ \\
Sural & SNCV & $49 \cdot 7(3 \cdot 2)$ & $53 \cdot 0(2 \cdot 6)$ & $53 \cdot 8(5 \cdot 0)$ \\
Ulnar & MDL (ms) & $47 \cdot 8(5 \cdot 6)$ & $50 \cdot 6(9 \cdot 9)$ & $51 \cdot 8(6 \cdot 7)$ \\
Peroneal & MDL (ms) & $3 \cdot 3(0 \cdot 4)$ & $3 \cdot 0(0 \cdot 2)$ & $3 \cdot 2(0 \cdot 3)$ \\
\hline
\end{tabular}

Table 4 Summary of the results of regression analysis (stepwise, backward)

\begin{tabular}{|c|c|c|c|c|c|}
\hline \multirow[b]{2}{*}{ Variables } & \multicolumn{3}{|c|}{$\begin{array}{l}\text { NCVs of upper extremities } \\
\text { (ulnar nerve) }\end{array}$} & \multicolumn{2}{|c|}{$\begin{array}{l}\text { NCVs of lower extremities } \\
\text { (stral nerve) }\end{array}$} \\
\hline & $M D L$ & $M N C V$ & Duration & $\begin{array}{l}\text { MNCV } \\
\text { (peróneal) }\end{array}$ & Duration \\
\hline $\begin{array}{l}\text { Duration of exposure } \\
\text { to cyclohexane }(y)\end{array}$ & $-(0.05)^{\star}$ & & & & \\
\hline $\begin{array}{l}\text { Duration of exposure } \\
\text { to } n \text {-hexane }(\mathrm{y}) \\
\text { Height }(\mathrm{cm}) \\
\text { Weight }(\mathrm{kg}) \\
\text { BMI }\left(\mathrm{kg} / \mathrm{m}^{2}\right)\end{array}$ & & $\begin{array}{l}-(0.05) \\
-(0.01) \\
+(0.01) \\
-(0.01)\end{array}$ & & & \\
\hline Skin temperature $\left({ }^{\circ} \mathrm{C}\right)$ & $-(0.01)$ & & $-(0.01)$ & & $-(0.05)$ \\
\hline $\begin{array}{l}\text { Cigarette consumption } \\
\text { (/day) }\end{array}$ & $+(0.05)$ & & & $-(0.01)$ & \\
\hline Adjusted $R^{2}$ & $0.51^{\star \star}$ & 0.42 & 0.36 & $0 \cdot 21$ & 0.24 \\
\hline
\end{tabular}

No significant relation was found for age or individual mean exposure to cyelohexane (ppm). ${ }^{\star} \mathrm{P}$ value of regression coefficient listed only if $\mathrm{P}<0.05$; ${ }^{\star}$ result of analysis listed only if adjusted $\mathrm{R}^{2} \geqslant 0.02 ;+=$ increase NCV or prolong MDL; $-=$ decrease.NCV or shorten MDL.
$88 \mathrm{ppm})$. The mean concentrations of toluene and $n$-hexane vapour in the breathing zone were 2-28 ppm (median $6 \mathrm{ppm}$ ) and not detectable respectively.

\section{NEUROPHYSIOLOGICAL STUDY}

The following neurophysiological variables were measured on the dominant arm and the leg of the same side by a standard method ${ }^{10}$ with an electromyograph (Sapphire 1P, Medelec, England). All the exposed workers and controls were examined from April to July in 1993 (the first study), and nine exposed workers were examined again in July 1994 (the second study, fig). All neurophysiological examinations were performed in an examination room of the factory by the same technician. The sensory ulnar nerve was stimulated antidromically, to shorten the time required for the study. Skin temperature was measured with a skin temperature indicator sticker (ProChecker, Kyowa Medex, Japan). Although the accuracy of the sticker was $1^{\circ} \mathrm{C}$, we used it for its simplicity.

The following indices were used and are defined as:

(1) MNCV: maximum nerve conduction velocity of the motor fibres of the ulnar nerve between the wrist and elbow and common peroneal nerve between the knee and ankle.

(2) MDL: motor distal latency of the ulnar nerve and common peroneal nerve.

(3) SNCVp: proximal conduction velocity of sensory fibres of the ulnar nerve between the elbow and wrist.

(4) SNCVd: distal conduction velocity of sensory fibres of the ulnar nerve between the wrist and 5th metacarpophalangeal joint and the sural nerve between the calf and foot.

(5) Amplitude: amplitude of maximum sensory nerve action potential of the ulnar nerve and sural nerve.

(6) Duration: duration of sensory nerve action potential of the ulnar nerve and sural nerve.

The nerves were supramaximally stimulated with a single pulse of $0.1 \mathrm{~ms}$ (for motor nerves) or $0.2 \mathrm{~ms}$ (for sensory nerves) at a frequency of $2 \mathrm{~Hz}$. The intensity of stimulation was $200-300 \mathrm{~V}$ (for motor nerves) or $50-150$ $\mathrm{V}$ (for sensory nerves).

\section{STATISTICAL CALCULATIONS}

Statistical analyses were carried out with Statview 4.0 procedures (Abacus Concepts). The $\chi^{2}$ test was used for comparing subjective symptoms. The paired $t$ test was used for comparing the NCV variables between workers and age and sex matched controls and between the first and second studies. To compare the higher and lower exposure groups with the controls, analysis of variance (ANOVA) was performed followed by Scheffe's multiple comparison test. ${ }^{11}$ Multiple regression analysis (stepwise, backward) was done to consider the relation between exposure indices and NCV or motor distal latency (MDL), after adjustment for other confounding factors. ${ }^{11}$ Differences were considered significant at $P<5 \%$. 
Table 5 Results of comparison between first and second studies

\begin{tabular}{|c|c|c|c|c|}
\hline & & \multicolumn{2}{|c|}{ Exposed workers followed up $(n=9)$} & \multirow[b]{2}{*}{$\begin{array}{l}\text { Controls } \\
(n=9)\end{array}$} \\
\hline & & $\begin{array}{l}\text { (1st study) } \\
\text { Mean (SD) }\end{array}$ & $\begin{array}{l}\text { (2nd study) } \\
\text { Mean (SD) }\end{array}$ & \\
\hline \multicolumn{2}{|c|}{ Time from the end of $n$-hexane $(y)$} & $1 \cdot 2(0 \cdot 6)$ & $2 \cdot 3(0 \cdot 6)$ & \\
\hline Ulnar & $\begin{array}{l}\text { MNCV } \\
\text { SNCVp } \\
\text { SNCVd }\end{array}$ & $\begin{array}{l}65.6(3.9) \\
69.5(5 \cdot 1) \\
53.4(5.2)\end{array}$ & $\begin{array}{l}67 \cdot 6(4 \cdot 2) \\
66 \cdot 8(4 \cdot 4) \\
52 \cdot 0(2 \cdot 6)\end{array}$ & $\begin{array}{l}66 \cdot 6(3 \cdot 0) \\
65 \cdot 6(3 \cdot 8) \\
50 \cdot 7(4 \cdot 4)\end{array}$ \\
\hline \multirow{6}{*}{$\begin{array}{l}\text { Peroneal } \\
\text { Sural } \\
\text { Ulnar } \\
\text { Peroneal } \\
\text { Ulnar }\end{array}$} & MNCV & $50.9(3.7)$ & $54.9(1.7)+\dagger$ & $55 \cdot 5(5 \cdot 4)$ \\
\hline & SNCV & $50 \cdot 7(6 \cdot 1)$ & $56 \cdot 3(3 \cdot 7) \dagger$ & $49 \cdot 7(8 \cdot 1)$ \\
\hline & MDL (ms) & $3.3(0.4)$ & $2.9(0.2)^{\star} t$ & $3 \cdot 3(0 \cdot 3)$ \\
\hline & MDL (ms) & $3.9(0.7)^{\star}$ & $3 \cdot 2(0 \cdot 2)^{\star \star} \dagger$ & $5 \cdot 3(1 \cdot 3)$ \\
\hline & Amplitude $(\mu \mathrm{V})$ & $22 \cdot 3(10 \cdot 0)$ & $22.8(8 \cdot 7)$ & $25 \cdot 1(15 \cdot 2)$ \\
\hline & Duration (ms) & $1 \cdot 8(0 \cdot 5)$ & $1.4(0 \cdot 1)^{\star} \dagger$ & $1 \cdot 8(0.3)$ \\
\hline \multirow{2}{*}{ Sural } & Amplitude $(\mu \mathrm{V})$ & $8.5(3.0)$ & $9.0(3.2)$ & $16 \cdot 3(7 \cdot 1)$ \\
\hline & Duration (ms) & $2.0(0.4)$ & $1.9(0.4)$ & $2 \cdot 1(0 \cdot 3)$ \\
\hline
\end{tabular}

$\star \mathrm{P}<0.05 v$ controls; ${ }^{\star \star} \mathrm{P}<0.01 v$ controls; $\mathrm{tP}<0.05$ 2nd $v$ 1st study; $\mathrm{H} \mathrm{P}<0.01 v$ 2nd $v$ 1st study.

One of the nine workers followed up had no history of exposure to $n$-hexane.

Pairs were matched at the time of the first study.

\section{Results}

WORKING CONDITIONS AND EXPOSURE

MEASUREMENTS

The individual external cyclohexane exposure ranged from five to $211 \mathrm{ppm}$, with a geometric mean (GM) of $28 \mathrm{ppm}$ (GSD 22-35 ppm). The individual cyclohexane exposure measured in the winter, six months before the first study, ranged from six to $720 \mathrm{ppm}$ with a GM of $77 \mathrm{ppm}$ (GSD 63-95 ppm). No improvement in equipment of the factory was made between that measurement and the present study, which was performed in hot weather in July and ventilation was better than in the winter because of open windows and many electric fans in the worksite.

The urinary cyclohexanol concentration ranged from 0.12 to $8.23 \mathrm{mg} / \mathrm{l}$, with a $\mathrm{GM}$ of $0.55 \mathrm{mg} / \mathrm{l}$ (GSD 0.45-0.68 mg/l).

\section{SUBJECTIVE SYMPTOMS}

There was no significant difference in subjective symptoms between workers exposed to solvent and matched controls. General fatigue was mentioned by nine of 18 workers exposed to cyclohexane and four of 15 controls $(P<0 \cdot 1)$. Headache and dizziness were complained of by $10 / 18$ and seven of 18 workers, and seven of 15 and four of 15 controls, respectively. An uneasy feeling was complained of by eight of 18 workers and five of 15 controls. For other chronic symptoms, there were smaller differences between workers and controls.

\section{NEUROPHYSIOLOGICAL FINDINGS}

The mean (SD, range) skin temperature was $32.4(1.6,26-35)$ in the arm and $31.8(1.9$, 26-34) in the leg.

Table 2 shows the means (SDs) of NCVs among cyclohexane workers and matched controls. These NCVs were measurements of the last study for each worker. There were no significant differences in MNCVs and SNCVs between 18 exposed workers and age and sex matched controls. The ulnar and peroneal MDLs were significantly shorter in workers than in controls $(P<0.05)$. Analysis of variance among different exposure levels did not show significant differences in any neurophysiological variables. The mean exposures of the higher exposure group ranged from 126 to $384 \mathrm{ppm}$ (median $156 \mathrm{ppm}$ ), and those of the lower exposure group ranged from 10 to 68 ppm (median $51 \mathrm{ppm}$, table 3). The ages, heights, and skin temperatures of all the groups were not significantly different.

Table 4 shows the summary of the results of multiple regression analysis. Eighteen workers exposed to cyclohexane and 18 age and sex matched controls were included in the analysis. Dependent variables were neurophysiological indices, and independent variables were age, height, weight, body mass index, cigarette consumption, skin temperature, exposure duration, and individual mean exposure to cyclohexane, and duration of exposure to $n$-hexane. Alcohol consumption (ethanol equivalent $\mathrm{ml} /$ week) was not included in the analysis because of the multicollinearity between duration of exposure to $n$-hexane and alcohol consumption. Duration of exposure to cyclohexane had a significant negative relation with ulnar MDL $(P<0.05)$. Individual mean exposure to cyclohexane, mean value of the present and past exposure data, did not have significant relations with any of the neurophysiological indices.

Table 5 shows the results of the follow up study on nine workers. The MNCV and SNCV of the legs were significantly improved in the second study compared with the first study $(\mathrm{P}<0.01, \mathrm{P}<0.05)$ and MDLs of the arms and legs were significantly shortened in the second study $(P<0.05)$. Comparison of the results of the second study with the measurements for age and sex matched controls $(n=9)$, showed that MDLs of workers in the second study had significantly better conduction.

\section{Discussion}

As the main result, measurements of NCV did not show obvious or subclinical polyneuropathy under almost exclusive exposure to cyclohexane, the personal concentration of which ranged from 5 to $211 \mathrm{ppm}$ (median $46 \mathrm{ppm}$ ).

An experimental study in rats showed no pathological changes in the tibial nerve, optical nerve, and medulla oblongata under the 2500 ppm, 30-week exposure to cyclohexane. ${ }^{3}$ This 
supports the validity of our study. On the other hand paralysis or neuropathological changes under exposure to cyclohexane were reported in humans and chickens. ${ }^{56}$ In those studies the exposure to cyclohexane was mixed with that to other solvents and the cyclohexane content of those solvents was less than $20 \%$. The airborne concentration of cyclohexane was also low, less than $10 \mathrm{ppm} .^{6}$ Whether the neuropathy is attributable to cyclohexane or not, further research is called for. Mutti reported a dose-dependent relation between the exposure of mixed solvents ( $n$ hexane, cyclohexane, methyl ethyl ketone) and subclinical neurophysiological changes. ${ }^{12}$ Although the mean exposure to cyclohexane was over $70 \mathrm{ppm}$, the concentration of $n$ hexane was also over $60 \mathrm{ppm}$. The effect of exposure to $n$-hexane could not be negligible. The exposure of the present study was lower than the time weighted average environmental limit in the United States and Japan, ${ }^{13} 300$ ppm and $150 \mathrm{ppm}$, respectively.

The improvement of NCVs in the follow up study was considered to be due to past exposure to $n$-hexane. Chang reported delayed MNCV of the arms and legs in workers not exposed to $n$-hexane for four years. ${ }^{14}$ Delayed worsening of $\mathrm{MNCV}$ was also found in five of 11 workers five to 10 months after the end of exposure to $n$-hexane. ${ }^{14}$ In the present study 12 workers had a history of exposure to $n$ hexane. The interval between the end of exposure to $n$-hexane and investigation was $0 \cdot 3-2 \cdot 6$ years, with a mean (SD) of $1.2(0.7)$ years in the first study. Therefore the first study was considered to have occurred during the recovery from subclinical neuropathy caused by $n$ hexane.

Although the level of exposure to $n$-hexane which induces delay of NCVs was said to be more than $100 \mathrm{ppm}$ in some reports, ${ }^{15-18} \mathrm{a}$ few studies reported that the delay of NCV was caused by less than $100 \mathrm{ppm}$ of $n$-hexane. ${ }^{1920}$ According to the health checks, the mean urinary concentration of 2,5-hexanedione was $9.03(4.44) \mathrm{mg} / 1$ in winter and $2.4(1.7) \mathrm{mg} / 1$ in summer, and $9.03 \mathrm{mg} / 1$ urinary 2,5 -hexanedione was equivalent to $87.8 \mathrm{ppm}$ of $n$-hexane as determined by Perbellini et al. ${ }^{21}$ Thus, we consider it was possible for past exposure to $n$ hexane to cause neurophysiological changes and that the results of the first study were affected by past exposure to $n$-hexane.

No neurophysiological indices were impaired at the second study. This agreed with a report describing the prognosis of $n$-hexane neuropathy to be good. ${ }^{14}$

Height, weight, body mass index, skin temperature, and cigarette consumption had independent significant relations with NCVs by multiple regression analysis in the present study. To detect effects of organic solvents on neurophysiological indices, these factors should be controlled as confounders. Skin temperature had significant relations with some neurophysiological indices, and improved nerve conduction in our study. Significantly positive relations between skin temperature and nerve conduction velocity were described in some previous studies. ${ }^{22} 23$ Differences in skin temperature between exposed workers and controls, however, were not significant. There are few reports on the relation between body build (height, weight, and BMI) and NCV other than in the median nerve. Takano et $a l,{ }^{24}$ Rivner et al, and Letz and Gerr reported a significant negative relation between height and NCV. ${ }^{22}{ }^{25}$ In our study, height had a significantly negative relation with ulnar MNCV as well (table 5) and exposed workers were significantly shorter than matched controls $(P<0.01)$. Ulnar MNCV could be slower in exposed workers than in controls if there was no difference in height between them. Studies that reported a significant relation between cigarette consumption and NCVs could not been found.

The urinary cyclohexanol concentration was referred to as a good index of exposure to cyclohexane by the study, ${ }^{7}$ which was performed in the same factory on 33 workers at the time of our first investigation. In particular urinary cyclohexanol measured by an enzymatic method corrected for specific gravity and creatinine had a significant positive relation with airborne cyclohexane. We examined the relation only in workers recruited for the neurophysiological study, but adding the data of the first and the follow up study we found the same results (regression coefficient $0 \cdot 8$, $P<0.0001$ )

In conclusion, no evidence of neurotoxic effects was found when almost the only occupational exposure was to cyclohexane for a relatively short time and at low concentrations (below the time weighted average threshold limit value of the United States). ${ }^{13}$

We thank our colleagues of Sapporo Medical University, Department of Neurology for technical assistance. This research was partly supported by a grant from the Japanese Ministry of Education, Science, and Culture.

1 Sandmeyer EE. Alicyclic hydrocarbons. In: George D. Clayton FEC, ed. Patty's industrial hygiene and toxicology, 3rd ed. New York: John Wiley, 1981;2B:3227-9.

2 Perbellini L, Brugnone F. Lung uptake and metabolism of cyclohexane in shoe factory workers. Int Arch Occup Environ Health 1980;45:261-9.

3 Frontali N, Amantini MC, Spagnolo A, Guarcini AM, Saltari MC. Experimental neurotoxicity and urinary metabolites of the C5-C7 aliphatic hydrocarbons used as glue solvents in shoe manufacture. Clin Toxicol 1981;18: 1357-67.

4 Mutti A, Cavaorta A. Neurophysiological changes in workers exposed to organic solvent. Scand $\mathcal{f}$ Work Environ Health 1982;8(suppl 1):136-41.

5 Franchini I, Cavatorta A, D'Errico M, et al. Studies on the etiology of the experimental neuropathy from industrial adhesive (glues). Experientia 1978;34:250-2.

6 Franco G, Moglia A, Ghittori S. Polineuropatia professionale riferibile a cicloesano. Med Lavoro 1979;2:118-24.

7 Yasugi T, Kawai T, Mizushima K, et al. Exposure monitoring and health effect studies of workers occupationally ing and health effect studies of workers occupationally exposed to cyclohexane

8 Kishi R, Harabuchi I, Katakura Y, Ikeda T, Miyake H. Neurobehavioral effects of chronic occupational exposure to organic solvents among Japanese industrial painters. Environ Res 1993;62:303-13.

9 Hirayama T, Ikeda M. Applicability of carbon felt to the dosimetry of solvent vapor mixture. Am Ind Hyg Assoc $\mathcal{F}$ 1979;40:1091-6.

10 Kimura J. Assessment of individual nerves. In: Kimura J, ed. Electrodiagnosis in diseases of nerve and muscle: principles and practice. Philladelphia: FA Davis, 1989:103-32.

11 Kleinbaum D, Kupper L, Muller K. Applied regression analysis and other multivariate methods. Boston: PWSKENT, 1988

12 Mutti A. Neurophysiological effects of long-term exposure to hydrocarbon mixtures. Arch Toxicol 1982;5(suppl): $120-4$. 
13 American Conference of Governmental Industrial Hygienists. Threshold limit values for chemical substances and physical agents and biological exposure indices. Cincinnati: ACGIH, 1993-4.

14 Chang Y. An electrophysiological follow up of patients with $n$-hexane polyneuropathy. Br f Ind Med 1991;48:12-7.

15 Herskowitz A, Ishii N, Schaumburg H. $n$-Hexane neuropathy. A syndrome occuring as a result of industrial exposure. N Engl f Med 1971;285:82-5.

16 Inoue T, Takeuchi Y, Takeuchi S. A health survey on vinyl sandal manufactures with high incidence of " $n$-hexane" intoxication. Fpn $\mathcal{F}$ Ind Health 1970;12:73-84.

17 Paulson G, Waylonis G. Polyneuropathy due to n-hexane. Arch Intern Med 1976;136:880-2.

18 Yamada S. Intoxication polyneuritis in the workers exposed to $n$-hexane. Fpn $\mathcal{F}$ Ind Health 1967;9:651-9.

19 Wang J-D, Chang Y-C, Kao K-P, Huang C-C, Lin C-C, Yeh W-Y. An outbreak of $n$-hexane induced polyneuropathy among press proofing workers in Taipei. Am $f$ ropathy among press pr.

20 Sanagi S, Seki Y, Sugimoto K, Hirata M. Peripheral ner- vous system functions of workers exposed to $n$-hexane at a low level. Int Arch Occup Environ Health 1980;47: 69-79.

21 Perbellini L, Brugnone F, Silvestri R, Gaffuri E. Measurement of the urinary metabolites of $n$-hexane,cyclohexane and their isomers by gas chromatography. Int Arch Occup Environ Health 1981;48:99-106.

22 Letz R, Gerr F. Covariates of human peripheral nerve function: I. Nerve conduction velocity and amplitude. Neurotoxicol Teratol 1994;16:95-104.

23 Halar EM, DeLisa JA, Brozovich FV. Nerve conduction velocity: relationship of skin, subcutaneous and intramuscular temperature. Arch Phys Med Rehabil 1980;61: 199-203.

24 Takano K, Kirchner F, Steinicke F, Langer A, Yasui H, Naito J. Relation between height and the maximum conduction velocity of the ulnar motor nerve in human subjects. Fpn $f$ Physiol 1991;41:385-96.

25 Rivner MH, Swift TR, Crout BO, Rhodes KP. Toward more rational nerve conduction interpretations: the effect of height. Muscle Nerve 1990;13:232-9.

\section{Occupational and Environmental Medicine and the electronic age}

OEM has an Email address which is 100632.3615@compuserve.com. We welcome contact by Email, including letters to the editor. Some of our reviewers already send us their reports by Email, helping to speed up the peer review process.

We are moving towards electronic publishing and for some months now we have been asking authors to send us their revised papers on disk as well as a hard copy. I am delighted to report that nearly all our authors are managing to comply with this request; far more than for other specialist journals in the BMJ Publishing group. Oddly enough, the few authors who have not sent us a disk version of their revised papers have been almost exclusively from the United Kingdom. I would be interested in suggestions for why this might be. Perhaps United Kingdom based authors read our correspondence and instructions less assiduously? Watch for revised Instructions to Authors.

The Editor 